\title{
TREINAMENTO CORPORAL DO ATOR COMO SUPORTE PARA O TRABALHO CORPORAL DO ATOR MANIPULADOR ${ }^{1}$
}

\author{
Marcelle Teixeira Coelho ${ }^{2}$ \\ Valmor Níni Beltrame (Orientador)
}

\begin{abstract}
RESUMO: Existem poucos estudos relacionados à formação corporal do atormanipulador e referente a um treinamento específico que desenvolva as habilidades requerentes para sua atuação. Inversamente, o treinamento corporal do ator é amplamente pesquisado, possuindo várias vertentes ou métodos. Partindo do pressuposto que o ator-manipulador também é um ator, o presente artigo se propõe a fazer uma reflexão sobre o treinamento corporal do ator desenvolvido nos últimos cem anos, que possa servir como suporte para o trabalho corporal do atormanipulador. Técnicas estas que possam fazer parte do seu treinamento, englobando tanto preparação física como crescimento pessoal, quanto a busca de uma ética corporal.
\end{abstract}

PALAVRAS-CHAVES: Treinamento; Ator-Manipulador; Expressividade.

Existem poucos estudos relacionados à formação corporal do atormanipulador e referente a um treinamento específico que desenvolva as habilidades requerentes para sua atuação. Inversamente, o treinamento corporal do ator é amplamente pesquisado, possuindo várias vertentes ou métodos. Partindo do pressuposto que o ator-manipulador também é um ator, o presente artigo se propõe a fazer uma reflexão sobre o treinamento corporal do ator que possa servir como suporte para o trabalho corporal do ator-manipulador.

O ator-manipulador é aquele que, através de seu corpo, anima, ou seja, dá vida ao objeto/boneco. A partir de suas habilidades corporais ele cria toda a

\footnotetext{
${ }^{1}$ Comunicação apresentada no XVII Congreso Internacional de Teatro Iberoamericano y Argentino, realizado de 5 a 9 de agosto de 2008 em Buenos Aires. Organizado pelo Instituto de Historia del Arte Argentino y Latinoamericano "Luis Ordaz", Facultad de Filosofía y Letras de la Universidad de Buenos Aires.

${ }^{2}$ Aluna regular do PPGT - Mestrado em Teatro/ CEART-UDESC. Ingressa no PPGT em março de 2008, sob orientação do prof. Dr.Valmor Níni Beltrame.
} 
movimentação necessária para que a natureza estática da matéria ganhe expressividade.

O objeto/boneco é a extensão do corpo do ator. Para que objeto se torne sujeito é necessário que seu manipulador aprenda a traduzir os movimentos do seu próprio corpo para o do boneco. Para isso, deve desenvolver primeiramente suas habilidades corporais, a fim de se apropriar de um repertório corporal que seja base da construção do movimento do seu boneco.

Em pesquisa realizada por Coelho (2003) ${ }^{3}$ pôde-se observar que os atoresmanipuladores, que possuem formação em dança, têm mais facilidade em manipular bonecos e de criar uma partitura de movimentos não-convencionais, do que os profissionais que não possuem este tipo de formação. Esta constatação só reforça a necessidade do desenvolvimento das habilidades corporais do bonequeiro, como uma forma de aprimorar a qualidade expressiva do movimento do boneco.

Outro aspecto relevante da pesquisa foi a constatação que estes profissionais têm sofrido de constantes dores musculares e lesões decorrentes de alguns fatores, entre eles: um grande número de apresentações, na qual , muitas vezes não há intervalo suficiente para a recuperação corporal; uma tendência à unilateralidade, ou seja, a predominância da utilização de um dos lados do corpo no ato da manipulação; o espaço reduzido de trabalho, onde muitas vezes necessita-se mais de um bonequeiro para manipular um boneco; a necessidade de se manter em uma postura extra-cotidiana durante a manipulação.

Por postura extra-cotidiana entendem-se aquelas atividades na qual nosso organismo não está acostumado a executar durante o dia a dia. Essas posturas exigem um esforço excessivo de certas partes do corpo a qual nosso organismo não está adaptado.

É neste contexto que podemos equiparar a importância do treinamento corporal do ator com o do ator-manipulador, pois ambos precisam de seu corpo como veículo para criação teatral. Não um corpo dual, em que o corpo e a mente

\footnotetext{
3 "A dança e a formação corporal do ator-manipulador". Pesquisa desenvolvida por mim, na PósGraduação - Especialização em Dança, Pontifícia Universidade Católica do Rio Grande do Sul /PUCRS.
} 
estão separados, mas sim em sua totalidade, na arte que emana desta pessoa em sua integralidade: 0 ator.

Vale lembrar as palavras de Decroux (apud. BURNIER, 2001:18) que coloca que o teatro é a arte de ator, e não do ator, pois é ele que o concebe e realiza. $\mathrm{Na}$ particularidade do teatro de formas animadas, o boneco é apenas o meio do qual o ator-bonequeiro estabelece relação com o público, porém é sua presença física atuante quem gera o significado da encenação.

No entanto, enquanto que no teatro com atores a preocupação com o desenvolvimento das habilidades corporais já vem de longa data, observa-se que com os bonequeiros esse processo ainda está se encaminhando de forma um tanto tímida. Podemos encontrar poucos estudos relacionados à formação corporal deste profissional, apesar de que muitos estudiosos ${ }^{4}$ desta arte coloquem o movimento como primordial ao fazer teatral.

Esse descaso em relação à formação corporal é decorrente de um entendimento equivocado que os atores-manipuladores têm em relação ao trabalho teatral, onde a preocupação é centrada no aspecto visual do boneco BELTRAME (2001:154). O corpo, como via de expressividade, é ainda relegado a um segundo plano, sendo muitas vezes negligenciado.

\section{0 treinamento}

Durante todo o século XX surgiram variadas abordagens para o treinamento corporal. Diferentes escolas e práticas buscaram desenvolver as habilidades corporais, influenciadas primeiramente pelos estudos da linguagem gestual de Delsarte e pela rítmica de Dalcroze, para depois buscarem na commedia dell'arte, no circo, na pantomima, na dança, nas práticas orientais como o tai chi chuan, entre outros, elementos para o desenvolvimento das qualidades expressivas do movimento.

${ }^{4}$ Meschke (1992), Artiles (1998), Bufano (1991) e Curti (2002).

DAPesquisa, Florianópolis, v.3 n.5, p.1113-1120, 2008. 
O estudo das diferentes práticas diferenciam-se entre si, pois algumas objetivam uma maior plasticidade corporal, enquanto que outras buscam desenvolver não somente as habilidades corporais, como também o ser humano em sua totalidade.

Para Béatrice Picon-Valin (2000:31) o treinamento deve ser baseado em exercícios físicos que ajudam ao ator a "aprofundar o conhecimento do seu esquema corporal, a testar e a dominar o seu gestual e os seus movimentos, para evoluir num espaço-tempo particular, o da cena".

Segundo Franco Ruffini (apud. Picon-Valin, 2000:35), o treinamento é um processo artificial, pelo qual o ator se adapta ao meio-cena. Ele se caracteriza por ser um trabalho contínuo, prolongado, coerente e independente dos espetáculos na qual o ator trabalha. Ou seja, o treinamento faz parte do processo de descoberta do ator, e não da personagem. Das descobertas de suas possibilidades corporais, da ampliação do seu movimento, da relação de seu corpo com o outro e com o espaço.

Este treinamento não é meramente físico. Vários encenadores, como Meyerhold e Barba, colocam que ele deve construir pontes entre o físico e o mental. Um ator não deve apenas praticar exercícios de forma repetitiva, baseada na cópia, como é feito pelos adeptos do balé clássico. $O$ ator tem que pensar.

O pensar não se refere apenas ao desenvolvimento intelectual e sim, desenvolver a inteligência corpóreo-cinestésica ${ }^{5}$, ou seja, "a capacidade de utilizar o próprio corpo de várias formas, altamente diferenciadas e hábeis, com propósitos expressivos, atendendo a objetivos intencionalmente determinados". (XAVIER, 1998:12). Um corpo como um todo, que interage com seu meio e consigo mesmo. Sensitivo e perceptivo tanto a estímulos exteriores (exteroceptivo), quanto aos referentes às sensações cinestésicas que nascem a partir do seu próprio corpo (proprioceptivo).

Para Jerzy Grotowski (apud PICON-VALIN, 2000:48) o treinamento vai além do desenvolvimento das habilidades corporais e mentais. Para o diretor polonês, o

\footnotetext{
${ }^{5}$ A inteligência corpóreo-cinestésica faz parte da Teoria das Inteligências Múltiplas, desenvolvida por Howard Gardner. Esta teoria aborda um conjunto de sete tipos de inteligências que equivalem tanto a procedimentos necessários para se fazer alguma coisa, quanto à perícia para utilizá-los. As outras inteligências são a musical, espacial, lingüística, lógica-matemática, interpessoal e intrapessoal.
} 
treinamento é também um meio de desenvolvimento pessoal, fora da profissão. Essa forma de pensamento, onde se busca a formação do ator em sua totalidade, não é nova. Na França, na primeira metade do século XX, tanto Copeau, como Jouvet e Dullin, buscavam a formação do ator "completo". Ambos primavam pelo desenvolvimento das habilidades físicas e mentais, mas, sobretudo, pela ética do ator.

\section{Sobre a ética do corpo}

Louvável a postura destes encenadores preocupados com desenvolvimento do ator como um ser atuante no mundo e não apenas interessados nos aspectos relacionados à encenação, mesmo que sejam questionáveis os meios pelos quais se possam alcançar estes objetivos. Porém, não se pode deixar de questionar de que forma este treinamento está sendo feito. Isto se refere ao ator, sendo ele manipulador ou não.

Durante todo o século $X X$ vimos surgir um infindável número de métodos diferentes de treinamento. Todos objetivando basicamente sensibilizar o ator e deixálo em estado de criatividade. Porém, observa-se que algumas práticas buscam levar o ator a este estágio a partir de um trabalho físico baseado na exaustão e na dor. $O$ treinamento desenvolvido por Grotowski, muito difundido nos anos 60 e 70 é um exemplo deste tipo de prática rigorosa.

Podemos observar no ator ocidental que a busca por uma técnica que vise desenvolver as habilidades físicas e mentais e a integração do ser como um todo, muitas vezes tem passado por cima de um elemento essencial: o seu próprio corpo.

Tendo em vista a fragilidade, a pouca durabilidade e resistente do corpo humano, a busca uma técnica para o trabalho do ator em que esses pressupostos não sejam ignorados é de fundamental importância, por ser esse corpo o veículo de linguagem deste profissional.

O treinamento excessivo, que não possui nenhum tipo de compensação pode fazer com que $o$ ator venha a ter uma vida de curta atuação, como os bailarinos $e$ atletas de alta performance. 
No que se refere ao ator-manipulador, o problema não está no tipo de treinamento desenvolvido e nas conseqüências que os excessos poderão causar, mas sim, na falta de uma prática que trabalhe as especificidades necessárias para uma boa atuação.

Enquanto os atores estão sempre na busca de diferentes formas de trabalhar o corpo, o artista bonequeiro ainda tem como prioridade a confecção, a plasticidade do boneco. Porém, o descaso com o corpo tem the causado problemas que podem o levar a restrições em sua movimentação e, conseqüentemente, a expressividade que este profissional deve imprimir ao boneco/objeto.

É neste contexto que as diversas metodologias corporais experenciadas pelos atores durante os últimos cem anos são um bom material para ser explorado pelos marionetistas. Não que queiramos comparar um com o outro, pois ambas as atividades possuem especificidades que lhes são próprias, mas sim estar aberto a conhecimentos já adquiridos, pinçando, não somente ao que se refere às práticas de treinamento do ator, mas também em outras áreas do conhecimento, técnicas para 0 desenvolvimento das habilidades expressivas do bonequeiro. Técnicas estas que possam fazer parte do seu treinamento, englobando tanto preparação física como crescimento pessoal, quanto a busca de uma ética corporal.

Stéphane Lupasco (apud WEIL1993:60) entende ética como um comportamento ao mesmo tempo físico, biológico e psicológico do homem na sua luta com fenômenos internos e externos, do sujeito e do objeto, do inconsciente e da consciência. Este conceito pode ser associado à abordagem enativa, na qual o sujeito não é apenas um observador desencarnado do mundo e sim, "o conjunto de um mundo e de uma mente a partir de histórias de diversas ações que caracterizariam um ser no mundo" (GREYNER, 2005:35).

\section{Referências bibliográficas:}

ASLAN, Odette. $O$ ator do século XX: Evolução da técnica/problema da ética. São Paulo: Perspectiva, 2003. 
AZEVEDO, Sônia. O papel do corpo no corpo do ator. São Paulo: Perspectiva, 2004.

BELTRAME, Valmor. Animar o inanimado: a formação profissional no teatro de bonecos. 2001. 269 f. Tese (Doutorado EM Artes Cênicas) - Escola de Comunicação e Artes, Universidade de São Paulo, São Paulo.

BURNIER, Luís O. A arte de ator: da técnica à representação. Campinas: Editora da UNICAMP, 2001.

COELHO, Marcelle. A dança e a formação corporal do ator-manipulador. 2002. 38p. Monografia (Especialização em Dança) - Faculdade de Educação Física e Ciências do Desporto. Pontifícia Universidade Católica do Rio Grande do Sul. Porto Alegre.

FALEIRO, José R. O corpo redescoberto. Texto.

FARABET, R. Ator. In: CORVIN, M. Dicionário Enciclopédico de Teatro. Tradução José Ronaldo FALEIRO.

FÉRAL, Josette. A Arte do Ator. In: Encenação e jogo do ator: entrevistas. Tomo 1: O espaço e o texto. Tradução de José Ronaldo FALEIRO.

GREYNER, Christine. O corpo: pistas para estudos indisciplinares. São Paulo: Annablume, 2005.

LE BRETON, David. A antropologia do corpo em cena. In: MÜLLER, C. O treinamento do Ator. Tradução de José Ronaldo FALEIRO.

PAYA, Farid. O treinamento, um anteparo. In: MÜLLER, C. O treinamento do Ator. Tradução de José Ronaldo FALEIRO.

DAPesquisa, Florianópolis, v.3 n.5, p.1113-1120, 2008. 
PICON-VALIN, Béatrice. L'acteur à l'exercice: de quelques expériences remarquables. In: MÜLLER, C. Le training de l'acteur. Arles: Actes Sud - Papiers Conservatoire National Supérieur d'Art Dramatique, 2000. (pp. 31-56)

VIEIRA, Jorge A. Rudolf Laban $e$ as modernas idéias científicas da complexidade. In: MOMMENSOHN, M \& PETRELLA, P. Reflexões sobre Laban, o mestre do movimento. São Paulo: Summus, (pp.91 - 103). 2006.

WEIS, Pierre. A nova ética. Rio de Janeiro: Rosa dos Tempos, 1993.

XAVIER, Telmo. Interação da inteligência corporal-cinestésica com a criatividade: uma abordagem no desempenho de tarefas motoras. 1998. 202p. Tese (Doutorado em Ciências do Movimento Humano) - Universidade Federal de Santa Maria, Santa Maria. 